\title{
Sublimation of $\mathrm{Li}_{60}{ }^{\star, \star \star}$
}

\author{
Eleanor E.B. Campbell ${ }^{1,2, a}$, Henry J. Chandler ${ }^{3}$, and Renald Schaub ${ }^{3}$ \\ ${ }^{1}$ EaStCHEM and School of Chemistry, University of Edinburgh, David Brewster Rd., Edinburgh EH9 3JF, UK \\ 2 School of Physics, Konkuk University, Seoul 05029, South Korea \\ ${ }^{3}$ EaStCHEM and School of Chemistry, University of St. Andrews, St. Andrews KY16 9ST, UK
}

Received 9 March 2020 / Received in final form 16 April 2020

Published online 16 June 2020

(C) The Author(s) 2020. This article is published with open access at Springerlink.com

\begin{abstract}
Experiments that probe the fundamental properties of endohedral fullerenes often require the preparation of molecular beams or thin films of the neutral molecules. It is challenging to cleanly sublime this class of molecules without producing some thermal degradation. We report combined gas phase and scanning tunnelling microscopy studies that probe the thermal decay of commercial $\left[\mathrm{Li}^{+} \mathrm{C}_{60}\right] \mathrm{PF}_{6}^{-}$in a quartz ampoule and provide treatment conditions that will allow the sublimation of intact, neutral $\mathrm{Li} @ \mathrm{C}_{60}$ accompanied by a well-characterised component of neutral $\mathrm{C}_{60}$. The decay of the material at appropriate temperatures can be modelled with the assumption of a second order decay process in the oven yielding Arrhenius parameters that can predict the ratio of $\mathrm{Li} @ \mathrm{C}_{60}$ to $\mathrm{C}_{60}$ in the sublimed material.
\end{abstract}

\section{Introduction}

Endohedral metallo-fullerenes, where at least one metal atom is encapsulated within the fullerene cage, have been the subject of many studies probing their formation, properties and potential applications [1,2]. The most commonly studied metallofullerenes are formed by growing the carbon cage around the metal atoms. In many cases the most energetically favourable cage does not have the same atomic structure as the equivalent empty fullerene cage and it has proved particularly challenging to isolate $\mathrm{M} @ \mathrm{C}_{60}$ using the conventional arc discharge or laser vapourisation methods [1]. An alternative way to produce $\mathrm{C}_{60}$ metallofullerenes is to implant the metal ion into the already-formed carbon cage. This method was used in early experiments to produce $\mathrm{Li} @ \mathrm{C}_{60}$ and has the advantage that the cage structure is the same as the well-known, icosahedral empty $\mathrm{C}_{60}$ cage [3]. Experiments on the isolated material showed a higher reactivity compared to $\mathrm{C}_{60}$ with a tendency for the purified material to oligomerise [4]. The production of $\mathrm{Li} @ \mathrm{C}_{60}$ has recently been upscaled and commercialised by using a plasma implantation technique $[5,6]$. It was shown that the purified material could be stabilised by forming a hexafluorophosphate salt [6]. The availability of macroscopic amounts of the purified material in the form of the salt has allowed many characterisation studies to be carried out [7]. The Li@ $\mathrm{C}_{60}$ molecule is particularly attractive to study from the fundamental

\footnotetext{
* Contribution to the Topical Issue "Atomic Cluster Collisions (2019)", edited by Alexey Verkhovtsev, Pablo de Vera, Nigel J. Mason, Andrey V. Solov'yov.

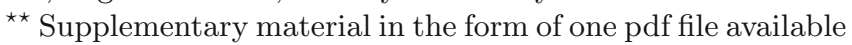
from the Journal web page at https://doi.org/10.1140/epjd/e2020-10146-0.

a e-mail: eleanor.campbell@ed.ac.uk
}

point of view due to the high symmetry of the encapsulating carbon cage and the off-centre position of the encapsulated metal with a relatively strong charge transfer component between the metal and the cage. However, it is challenging to produce isolated molecules for detailed study either in the gas phase or deposited in the form of thin films.

We have recently combined gas phase studies using mass spectrometry and photoelectron spectroscopy with scanning tunnelling microscopy to obtain insight into the socalled Super-Atom Molecular Orbital states of the molecule [8] and showed that it is possible to demonstrate multistate switching in a single $\mathrm{Li} @ \mathrm{C}_{60}$ molecule with 14 distinct switching states [9]. These experiments required the preparation of a clean beam of $\mathrm{Li} @ \mathrm{C}_{60}$ molecules (containing some proportion of empty $\mathrm{C}_{60}$ ) that was prepared by heating the commercial $\left[\mathrm{Li}^{+} @ \mathrm{C}_{60}\right] \mathrm{PF}_{6}^{-}$material in a quartz ampoule at elevated temperatures. In this paper we present results of combined gas phase and scanning tunnelling microscopy experiments that characterise the thermal decay of the material within the oven. The behaviour can be modelled empirically with the assumption of a second order decay process occurring in the oven, providing Arrhenius parameters that can predict the ratio of $\mathrm{Li} @ \mathrm{C}_{60} / \mathrm{C}_{60}$ in the evaporated molecular beam.

\section{Methods}

An effusive molecular beam of $\mathrm{Li} @ \mathrm{C}_{60}$ was produced by heating $\left[\mathrm{Li}^{+} @ \mathrm{C}_{60}\right] \mathrm{PF}_{6}^{-}$(Idea International Inc., > $>0 \%$ purity) in a small quartz capillary inserted into a heated molybdenum cylinder within an UHV vacuum chamber (background pressure $10^{-8} \mathrm{mbar}$ ). It is important to ensure that hot fullerene materials do not make contact 
with heated metals to avoid extensive destruction of the cage and amorphization of the material in the oven, this is particularly important for metallo-endohedral fullerenes. Laser-desorption FTICR mass spectrometry of the starting material in both the positive and negative mode showed only minor traces of $\mathrm{C}_{60}$ with the non-fullerene content being predominantly the stabilising anions and solvent residues. As we have shown previously $[8,9]$ neutral $\mathrm{Li} @ \mathrm{C}_{60}$ is evaporated from the oven along with impurities and some $\mathrm{C}_{60}$. The material is typically heated to a temperature of ca. $590 \mathrm{~K}$ for at least $20 \mathrm{~h}$ to remove solvent residue and other impurities before gas phase experiments such as photoelectron spectroscopy [8] are carried out. The neutral species are ionised with an ultrashort pulse laser in the extraction region of a simple linear Wiley-MacLaren time-of-flight mass spectrometer. The positively charged ions are detected at an MCP detector situated $42 \mathrm{~cm}$ from the interaction region. The time-offlight signal was recorded with a $500 \mathrm{MHz}$ oscilloscope. All spectra reported in this paper were collected for $4 \times 10^{5}$ laser shots. Unless otherwise stated, the ions were produced with the third harmonic of a $120 \mathrm{fs}$ Ti:Sapphire laser $(267 \mathrm{~nm})$. This wavelength efficiently ionises both $\mathrm{C}_{60}$ and $\mathrm{Li} @ \mathrm{C}_{60}$ with 2 photons (ionisation energies of $7.6 \mathrm{eV}$ [10] and $6.5 \mathrm{eV}$ [11], respectively) and reduces the influence of fragmentation. The relative photoionisation efficiencies are known to be dependent on the wavelength. The laser power, unless otherwise stated was within the range $3-3.5 \mathrm{~mW}$ for all reported measurements. This power produced only very small amounts of fullerene fragments.

The scanning tunnelling microscopy (STM) images were obtained in an ultrahigh vacuum surface analysis system with a base pressure below $10^{-10}$ mbar, consisting of a preparation chamber allowing for standard sample preparation and molecular deposition, and a microscope chamber housing a CreaTec low-temperature STM. STM acquisition was performed at liquid helium temperature with electrochemically etched $\mathrm{W}$ tips and applying the bias voltage to the sample (tip remaining grounded). Imaging was achieved using the constant current mode. For the results reported here, the fullerene molecules were deposited on $\mathrm{Au}$ (111). The fullerene material was heated in a molecular evaporator consisting of a small quartz tube surrounded by a heating element. The evaporator was degassed at ca. $570 \mathrm{~K}$ for several hours prior to experiment, similar to the treatment used for the mass spectrometry experiments. The molecules were then dosed for $4 \mathrm{~min}$. at ca. $665 \mathrm{~K}$ at a partial pressure of $5 \times 10^{-8} \mathrm{mbar}$ and then annealed on the surface at $570 \mathrm{~K}$ for $30 \mathrm{~s}$ to form large hexagonally close-packed islands by mass diffusion before being quenched down to liquid He temperature for STM imaging.

\section{Results and discussion}

\subsection{Mass spectrometry}

Figure 1 shows the development of the positive ion mass spectra produced by ionising the neutral evaporated material from the quartz oven with $267 \mathrm{~nm}$, ultrashort

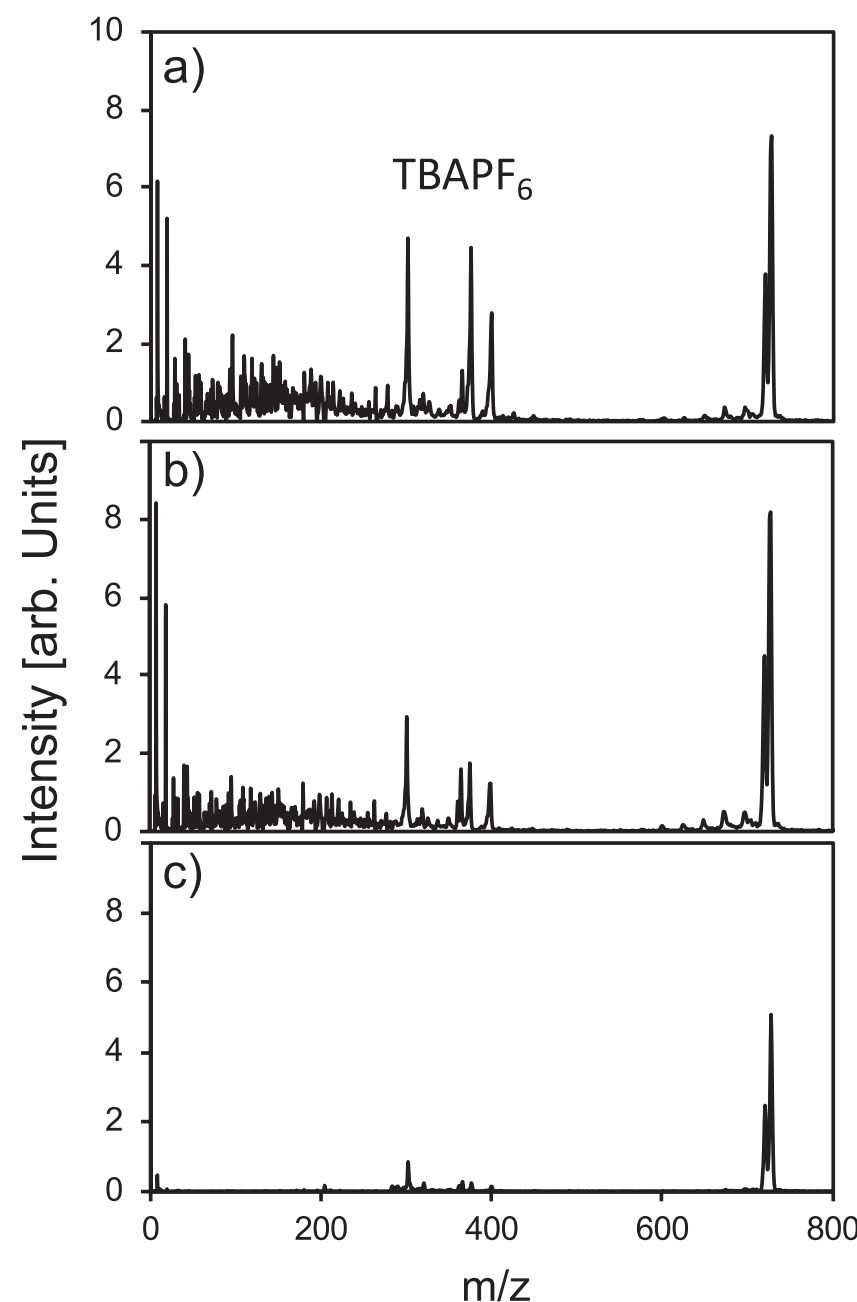

Fig. 1. Positive ion time-of-flight mass spectra of the material emitted from the oven at a temperature of $590 \mathrm{~K}$ using $267 \mathrm{~nm}$ $100 \mathrm{fs}$ laser pulses. (a) On first reaching the given temperature. (b) After $40 \mathrm{~min}$ heating at $590 \mathrm{~K}$. (c) After a total of $15 \mathrm{~h}$ heating.

laser pulses. The evaporation was carried out at an oven temperature of $590 \mathrm{~K}$. There are strong signals that can be attributed to tetrabutyl ammonium phosphorus hexafluoride along with other impurities including $\mathrm{H}_{2} \mathrm{O}^{+}$. As the material continues to be heated at $590 \mathrm{~K}$ the intensities of the impurities and peaks due to $\mathrm{TBAPF}_{6}$ decrease. Figure 1c shows the spectrum obtained after cooling and reheating, with a total of $15 \mathrm{~h}$ heating at $590 \mathrm{~K}$. Here the impurity peaks have almost disappeared.

In order to check whether the empty $\mathrm{C}_{60}$ is coming from the oven or is produced via fragmentation due to the laser excitation, we show the detected integrated intensity ratio $\mathrm{Li} @ \mathrm{C}_{60}^{+} / \mathrm{C}_{60}^{+}$(summing over all fullerene parent and fragment species) as a function of laser power in Figure 2 for two similar oven temperatures $(600 \mathrm{~K}$ and $608 \mathrm{~K})$ measured on different days, after the initial "de-gassing" process had been completed by heating for ca. $20 \mathrm{~h}$ at $590 \mathrm{~K}$. The ratio is constant for both measurement series showing that the production of empty fullerenes is not a consequence of the ionisation process. The lower value for 


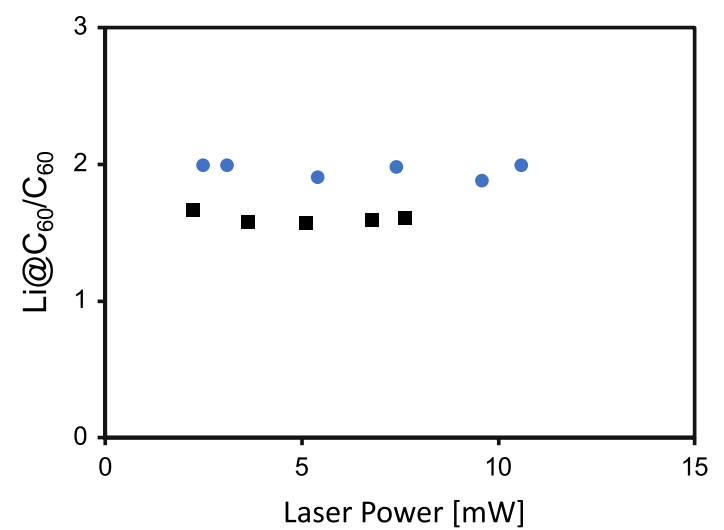

Fig. 2. Laser power dependence of the measured $\mathrm{Li} @ \mathrm{C}_{60}^{+} / \mathrm{C}_{60}^{+}$ ratio in the mass spectra. Circles: oven temperature of $600 \mathrm{~K}$. Squares: oven temperature of $608 \mathrm{~K}$ after the same material was heated to $623 \mathrm{~K}$, cooled and reheated 6 days later. The ratio does not change significantly with laser power over the measured range but does change between measurements.

the ratio obtained at $608 \mathrm{~K}$ is due to the time the material has been heated in the oven between measurement series, as will be discussed later.

The ratio of $\mathrm{Li} @ \mathrm{C}_{60}^{+}$to $\mathrm{C}_{60}^{+}$that is observed in the mass spectra changes with time and oven temperature, as well as with laser wavelength. The laser wavelength effect can be attributed to different photoionisation probabilities for $\mathrm{Li} @ \mathrm{C}_{60}$ and $\mathrm{C}_{60}$. As discussed above in Section 2, we choose $267 \mathrm{~nm}$ to minimise this effect (only 2 photons required to ionise each molecule) and also to reduce the likelihood of fragmentation due to multiple photon absorption. However, we do not know what the relative detection efficiency is. The influence of heating and exposure to air after heating can be seen in Figure 3. Figure 3a shows the $\mathrm{Li} @ \mathrm{C}_{60}^{+}$component to be stronger than the $\mathrm{C}_{60}$ component on first heating to a temperature of $688 \mathrm{~K}$. The material was then heated to $767 \mathrm{~K}$ where there is a significant change in the ratio of the two intensities with $\mathrm{Li} @ \mathrm{C}_{60}^{+}$ now significantly smaller than $\mathrm{C}_{60}^{+}$(see further discussion in Sect. 3.4). The ratio continues to decrease as the material is cooled back down to $644 \mathrm{~K}$. The same material was then cooled down to room temperature and removed from the vacuum chamber for a period of 12 days before being re-examined. Figure $3 d$ shows the resulting mass spectrum on re-heating the material to $668 \mathrm{~K}$, there is a further significant drop in the intensity of $\mathrm{Li} @ \mathrm{C}_{60}^{+}$and the achievable intensity for similar laser ionisation conditions is noticeably less (however, note that the absolute intensity values in Fig. 3 are comparable for (a)-(c) but not for (d) due to slightly different apparatus settings).

There is clearly a change in the heated material, particularly when exposed to atmosphere after heating, with a component of insoluble material within the oven in addition to the changed mass spectra. Raman spectroscopy confirms significant changes at the surface of the material left in the oven after heating, with evidence for amorphisation of the material (S.I. Fig. S1). However, MALDI mass spectrometry of the soluble component of the remaining material (sonicated in dichlorobenzene for $20 \mathrm{~min}$ prior to filtering) shows identical spectra to the starting material (S.I. Fig. S2), indicating that the material changes are predominantly at the surface of the material in the oven. This is also known to be the case for empty $\mathrm{C}_{60}$ where studies have shown that the vapour pressure can decrease significantly on successive heating cycles accompanied by the appearance of an insoluble amorphous residue, particularly in the presence of any organic solvent residue in the starting material $[12,13]$.

In addition to the decreasing $\mathrm{Li} @ \mathrm{C}_{60}^{+}$intensity with time at elevated temperatures, there is an accompanying increase in the intensity of $\mathrm{Li}^{+}$in the mass spectra. If we assume that the isolated $\mathrm{Li}^{+}$signal is a consequence of the destruction of $\mathrm{Li} @ \mathrm{C}_{60}$ within the oven (there is no non-endohedral Li in the starting material) we can use the temperature dependence to extract an effective activation energy for the appearance of $\mathrm{Li}$ and thus the destruction of the endohedral species, assuming that the Li efficiently escapes from the oven. An Arrhenius-type plot of the natural logarithm of the $\mathrm{Li}^{+}$intensity measured in the mass spectra multiplied by temperature (proportional to the partial pressure of $\mathrm{Li}$ in the oven) [14] as a function of inverse temperature is shown in Figure 4. This yields an activation energy for the cage destruction within the oven of $1.27 \pm 0.05 \mathrm{eV}$ (errors are the $95 \%$ confidence limits from the straight line fit). This value is remarkably close to the activation energy determined previously for Li loss from the dimerised endohedral species in solution $(1.1 \pm 0.2 \mathrm{eV})$ [15]. It is much lower that the value of $5.4 \pm 0.2 \mathrm{eV}$ obtained for release of Li from the isolated gas phase cationic endohedral molecules that is similar to the threshold energy for $\mathrm{Li}^{+}$implantation in $\mathrm{C}_{60}$ [16] and the bias voltage at which Li loss from the $\mathrm{C}_{60}$ cage is observed in STM experiments [9]. The determined activation energy for the material within the oven is thus not a consequence of a simple unimolecular decay reflecting the loss of Li from an intact $\mathrm{C}_{60}$ cage but is a consequence of more complex reactions with impurity species in the oven. However, the "effective" activation energy that is determined in this way can give a useful estimation/prediction of the thermal stability of the endohedral material in the oven.

\subsection{Enthalpy of sublimation}

The enthalpy of sublimation can be determined from the intensity of the molecular species in the mass spectra. We follow the mass spectrometry procedure used previously to determine the enthalpy of sublimation of $\mathrm{C}_{60}, \mathrm{C}_{70}[13,17]$ and $\mathrm{Er}_{3} \mathrm{~N} @ \mathrm{C}_{80}$ [18]. The ion intensity measured in the mass spectrometer is proportional to the vapour pressure divided by the temperature. A plot of $\ln$ (Intensity $\times$ Temperature) as a function of inverse temperature should yield a straight line with the gradient determined by the activation energy for vapourisation, $-E_{\mathrm{a}} / R$ where $R$ is the gas constant. The $E_{\mathrm{a}}$ value is equivalent to the internal energy of sublimation, $\Delta_{\text {sub }} U$ at the average temperature $T_{\mathrm{av}}$ for which the measurement was carried out (since sublimation occurs into vacuum). This is converted to the enthalpy of sublimation at $T_{\mathrm{av}}, \Delta_{\mathrm{sub}} H_{T_{\mathrm{av}}}$ by addition of $R T_{\mathrm{av}}$ [19]. To convert $\Delta_{\text {sub }} H_{T_{\mathrm{av}}}$ to $\Delta_{\mathrm{sub}} H_{298}$ we consider the difference 

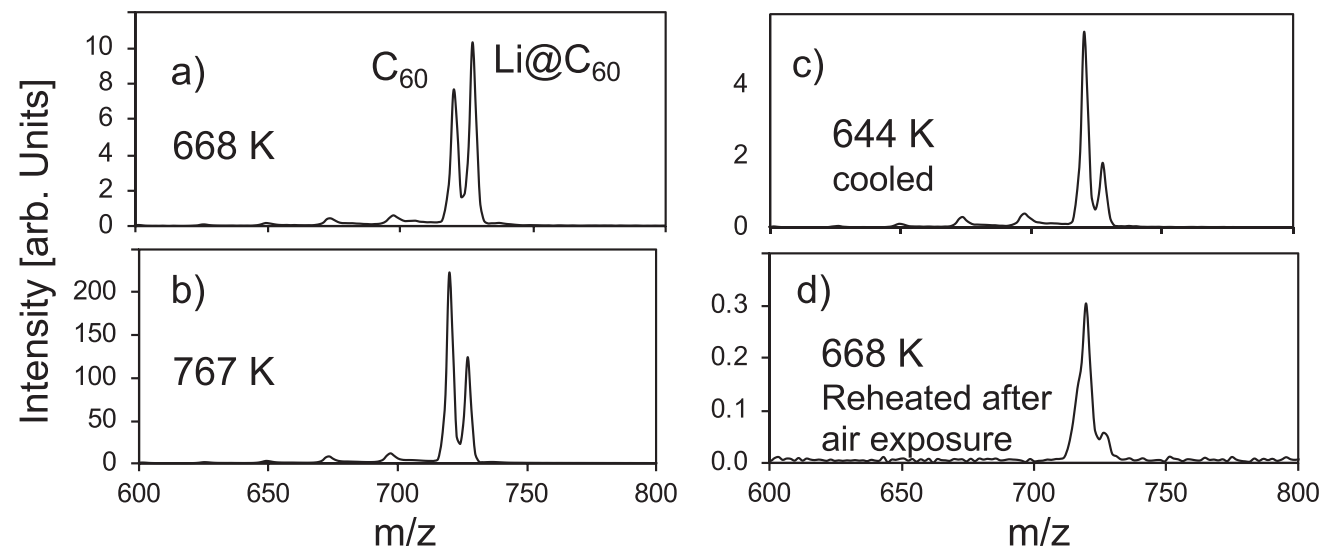

Fig. 3. Time series of mass spectra showing the decay of the detected $\mathrm{Li} @ \mathrm{C}_{60}^{+} / \mathrm{C}_{60}^{+}$ratio. (a) On first heating to $668 \mathrm{~K}$. (b) Further heating to $767 \mathrm{~K}$. (c) Cooling back down to $644 \mathrm{~K}$. (d) Reheating to $668 \mathrm{~K}$ after cooling to room temperature and exposing the oven to air for 12 days. The intensity scales for (a)-(c) are comparable.

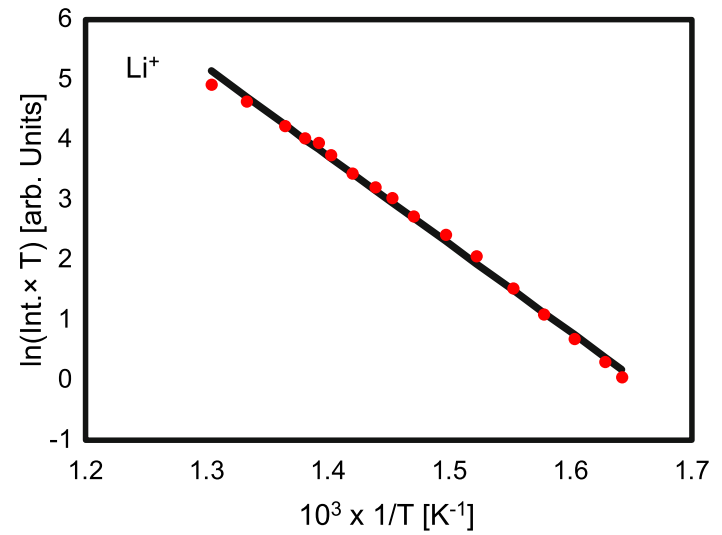

Fig. 4. Arrhenius-type plot of the $\mathrm{Li}^{+}$flux as a function of inverse temperature. The fitted line corresponds to an activation energy of $1.27 \pm 0.05 \mathrm{eV}$.

in heat capacity between the gas and solid, $\Delta_{\mathrm{S}}^{\mathrm{g}} C_{\mathrm{P}}$, at constant pressure, $\Delta_{\mathrm{sub}} H_{298}=\Delta_{\mathrm{sub}} H_{T_{\mathrm{av}}}-\Delta_{\mathrm{s}}^{\mathrm{g}} C_{\mathrm{P}}\left(T_{\mathrm{av}}-298\right)$, with $\Delta_{\mathrm{s}}^{\mathrm{g}} C_{\mathrm{P}}=-37.4 \mathrm{~J} \mathrm{~K}^{-1} \mathrm{~mol}^{-1}[20]$.

Figure 5 shows a plot of the flux of $\mathrm{Li} @ \mathrm{C}_{60}$ and $\mathrm{C}_{60}$ from the endohedral material for two heating cycles as well as the results from a pure $\mathrm{C}_{60}$ sample from the first heating cycle for comparison. The results from the different measurement series have been shifted vertically on the plot for clarity. The extracted values for the enthalpies of sublimation are summarised in Table 1. The value obtained for the pure $\mathrm{C}_{60}$ material (99.95\% purity, SES research), $\Delta_{\text {sub }} H_{298}=156 \pm 18 \mathrm{~kJ} \mathrm{~mol}^{-1}$, is consistent with previous reported measurements for a first heating cycle [18]. Note that, as discussed in the literature $[12,13,18]$, the value obtained for the enthalpy of sublimation depends strongly on how the material was thermally treated prior to measurement. In this case it was heated at $368 \mathrm{~K}$ for 3 days to remove solvent residue. As is usual for fullerene materials, the second and subsequent heating cycles produce a significantly lower vapour pressure than the first cycle. The deviation of the data points at high temperature from the straight-line fit is indicative of changes occurring within

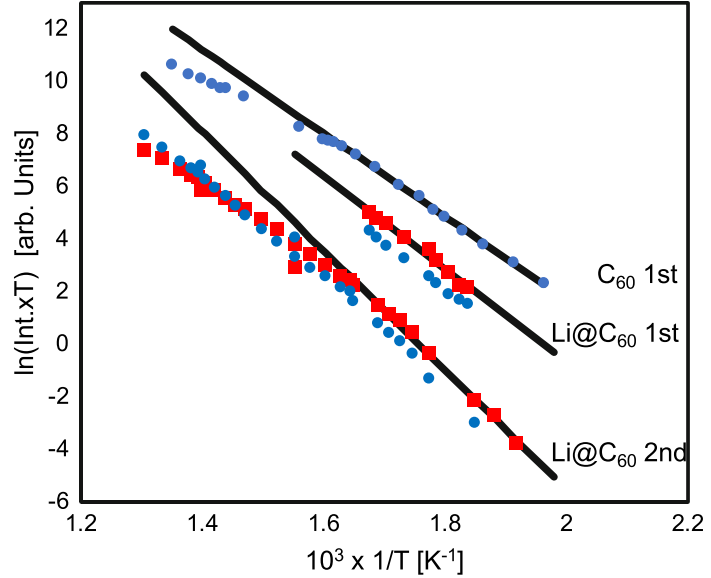

Fig. 5. Temperature dependence of the molecular flux (proportional to intensity $\times$ temperature) for 3 measurement series: pure $\mathrm{C}_{60}$ on the first time of heating after low temperature treatment to remove solvent residue; $\mathrm{Li} @ \mathrm{C}_{60}$ on the first time of heating after low temperature treatment to remove solvent residue ( $\mathrm{Li} @ \mathrm{C}_{60}$ 1st) and a subsequent heating cycle for the same material $\left(\mathrm{Li} @ \mathrm{C}_{60}\right.$ 2nd) while keeping the material in high vacuum between experimental runs. Squares: $\mathrm{Li}_{6} \mathrm{C}_{60}^{+}$ flux; circles: $\mathrm{C}_{60}^{+}$flux. The full lines are regression analysis fits to the experimental data used to determine the enthalpies of sublimation. The data points have been shifted vertically for clarity.

the oven that reduce the vapour pressure. This can also be seen from the results from the Li@ $\mathrm{C}_{60}$ material where the extracted $\Delta_{\text {sub }} H_{298}$ increases from $162 \pm 17 \mathrm{~kJ} \mathrm{~mol}^{-1}$ on the first heating cycle to $203 \pm 11 \mathrm{~kJ} \mathrm{~mol}^{-1}$ on the second cycle. The enthalpy of sublimation determined for $\mathrm{C}_{60}$ that is emitted from the endohedral fullerene material in the low temperature range where the values have been determined is identical to that for $\mathrm{Li} @ \mathrm{C}_{60}$ within the $95 \%$ confidence limits of the fits. It is also the case that the enthalpy of sublimation for pure $\mathrm{C}_{60}$ on the first heating cycle is the same as for $\mathrm{Li} @ \mathrm{C}_{60}$ and $\mathrm{C}_{60}$ from the endohedral material within the experimental errors. The 
Table 1. Values of the enthalpy of sublimation (in units of $\mathrm{kJ} \mathrm{mol}^{-1}$ ) extracted from the data shown in Figure 5 . The error limits represent the $95 \%$ confidence levels of the regression analysis.

\begin{tabular}{lccccc}
\hline Sample & $T_{\mathrm{Av}}[\mathrm{K}]$ & $\mathrm{Li} @ \mathrm{C}_{60} \Delta_{\text {sub }} H_{T_{\mathrm{av}}}$ & $\mathrm{Li} @ \mathrm{C}_{60} \Delta_{\text {sub }} H_{298}$ & $\mathrm{C}_{60} \Delta_{\text {sub }} H_{T_{\mathrm{av}}}$ & $\mathrm{C}_{60} \Delta_{\text {sub }} H_{298}$ \\
\hline $\mathrm{Li} @ \mathrm{C}_{60}$ (1st heating) & 572 & $152 \pm 17$ & $162 \pm 17$ & $152 \pm 8$ & $162 \pm 8$ \\
$\mathrm{Li} @ \mathrm{C}_{60}$ (2nd heating) & 566 & $193 \pm 11$ & $203 \pm 11$ & $220 \pm 17$ & $230 \pm 17$ \\
$\mathrm{C}_{60}$ (1st heating) & 554 & - & - & $146 \pm 18$ & $156 \pm 18$ \\
\hline
\end{tabular}

a)

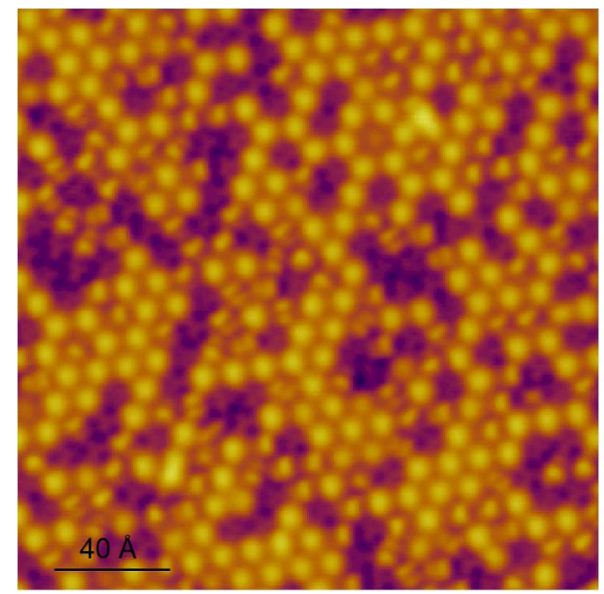

b)

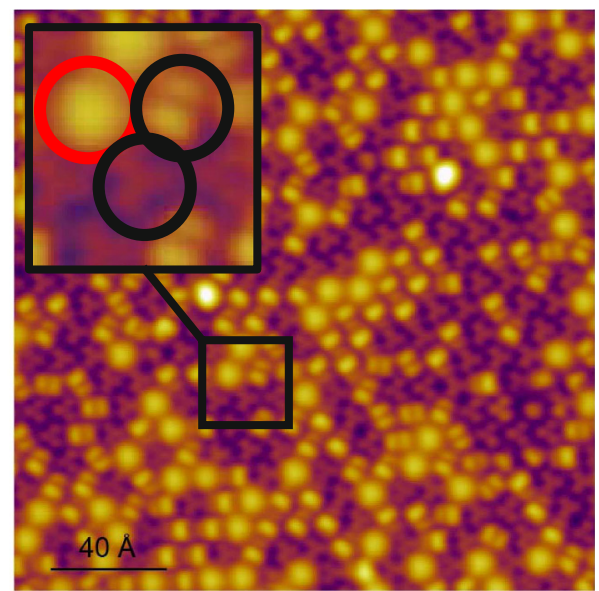

Fig. 6. STM constant current images of fullerene islands deposited from $\left[\mathrm{Li}^{+} \mathrm{C}_{60}\right] \mathrm{PF}_{6}^{-}$exposed to thermal pre-treatment at $570 \mathrm{~K}$ in a quartz evaporator prior to deposition. The images were taken at a bias voltage of $+2.5 \mathrm{~V}$ that allows the Li@C 60 molecules (diffuse circular image) to be distinguished from the empty $\mathrm{C}_{60}$ molecules (dumbbells and trefoils). (a) Pre-heating at $570 \mathrm{~K}$ for $6.5 \pm 0.5 \mathrm{~h}, 42 \pm 3 \% \mathrm{Li} @ \mathrm{C}_{60}$. (b) Pre-heating at $570 \mathrm{~K}$ for $105 \pm 5 \mathrm{~h}, 13 \pm 3 \%$ Li@C60. Insert illustrates the three distinct structures: red circle: $\mathrm{Li} @ \mathrm{C}_{60}$; black circles: $\mathrm{C}_{60}$ (dumbbell and trefoil).

results show a similar trend to those obtained from studies of the sublimation of $\mathrm{Er}_{3} \mathrm{~N} @ \mathrm{C}_{80}$ [18] where the sublimation enthalpy for an average temperature of ca. $870 \mathrm{~K}$ was $165 \mathrm{~kJ} \mathrm{~mol}^{-1}$ on the first heating cycle increasing to $237 \mathrm{~kJ} \mathrm{~mol}^{-1}$ for subsequent heating cycles at an average temperature of $955 \mathrm{~K}$.

\subsection{Scanning tunnelling microscopy images}

In our previous studies of scanning tunnelling spectroscopy of $\mathrm{Li} @ \mathrm{C}_{60}$ deposited on $\mathrm{Au}(111)[8,9]$ we showed that it was possible to distinguish $\mathrm{Li} @ \mathrm{C}_{60}$ from $\mathrm{C}_{60}$ by imaging the molecules at a bias voltage of $+2.5 \mathrm{~V}$. The thermal treatment of the endohedral fullerene material prior to deposition is similar to that used for the gas phase experiments (to ensure that deposition of non-fullerene material from the oven is minimised) and this leads to a mixture of $\mathrm{Li} @ \mathrm{C}_{60}$ and $\mathrm{C}_{60}$ being deposited on the gold surface. The fullerene molecules form hexagonally close-packed islands. At negative bias voltages (imaging the filled states) the molecules are indistinguishable, however at the positive bias voltage of $+2.5 \mathrm{~V}$, the S-SAMO orbital of $\mathrm{Li}_{0} \mathrm{C}_{60}$ is accessed and the endohedral molecules appear to "light up" showing a diffuse circular image with no apparent structure [9]. It is therefore possible to directly count the endohedral and empty fullerenes that are deposited on the substrate for a given thermal treatment in the oven.
Figure 6 shows two example images taken with a $+2.5 \mathrm{~V}$ bias on fullerene islands that were deposited after different thermal pre-treatment. The material deposited in Figure $6 \mathrm{a}$ was de-gassed at a temperature of $570 \mathrm{~K}$ for $6.5 \pm 5 \mathrm{~h}$ while the material deposited in Figure $6 \mathrm{~b}$ was treated at the same temperature for $105 \pm 5 \mathrm{~h}$. The diffuse circular structures are $\mathrm{Li} @ \mathrm{C}_{60}$ while the smaller "dumbbell" and darker "trefoil" structures are due to empty $\mathrm{C}_{60}$ that has different orientations on the surface [9]. It is clear from these images that there are significantly smaller amounts of $\mathrm{Li}_{0} \mathrm{C}_{60}$ deposited in Figure 6b. Statistical analysis of the deposited islands for the two different pre-deposition thermal treatments yields $42 \pm 3 \% \mathrm{Li}_{0} \mathrm{C}_{60}$ for the shorter thermal treatment and $13 \pm 3 \% \mathrm{Li}_{0} \mathrm{C}_{60}$ for the longer thermal treatment. The STM analysis gives additional information about the decay of the endohedral material. Although we have very few data points we can estimate the decay rate within the oven. There are many different models to describe the kinetics of solid state reactions depending on the most probable mechanism for a particular case [21]. Our data do not fit well to a simple first order reaction but can be reasonably fitted by e.g. the assumption of a second order reaction or a more complex 3D diffusion model. Here, we do not have sufficient data points to determine the reaction mechanism but are mainly concerned with comparing the extracted rate constant at the de-gassing temperature used for the STM experiments with the decay behaviour observed from the gas phase mass spectrometry results in order to 


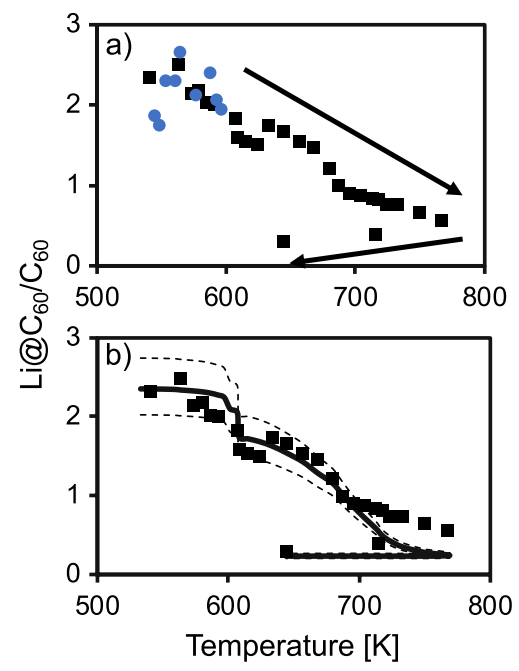

Fig. 7. Measured intensity ratios for $\mathrm{Li} @ \mathrm{C}_{60}^{+}$and $\mathrm{C}_{60}^{+}$for the measurement series in Figure 5. (a) Circles: first heating cycle; squares: second heating cycle. Arrows indicate the order of measurements. (b) Data from second measurement cycle compared to the results of the modelled decay. Full line: $A=3.8 \times 10^{6} \mathrm{~s}^{-1}, E_{\mathrm{a}}=1.285 \mathrm{eV}$, second order rate constant $k(570 \mathrm{~K})=1.74 \times 10^{-5} \mathrm{~s}^{-1}$. Upper dashed: $A=3.6 \times 10^{6} \mathrm{~s}^{-1}$, $E_{\mathrm{a}}=1.29 \mathrm{eV}, k(570 \mathrm{~K})=1.5 \times 10^{-5} \mathrm{~s}^{-1}$; Lower dashed: $A=4.0 \times 10^{6} \mathrm{~s}^{-1}, E_{\mathrm{a}}=1.28 \mathrm{eV}, k(570 \mathrm{~K})=2.0 \times 10^{-5} \mathrm{~s}^{-1}$. The detection probability, that influences the absolute value of the ratio detected in the gas phase experiments was found to be six times larger for $\mathrm{Li} @ \mathrm{C}_{60}$ than for $\mathrm{C}_{60}$.

determine an empirical estimation of the extent of decay of the endohedral fullerene material as a function of thermal treatment. Using a second order decay model, the rate constant determined from the STM measurements is $k=(1.7 \pm 0.2) \times 10^{-5} \mathrm{~s}^{-1}$ at $570 \mathrm{~K}$, where the error limits are given by the standard error of the regression fit. Note that the value of the rate constant determined from the data is dependent on the model assumed. Taking the activation energy for the decay from the gas phase measurements $(1.27 \pm 0.05 \mathrm{eV})$ allows us to then estimate the range of possible pre-exponential factors for the decay $\left(A \approx 9 \times 10^{5}-8.7 \times 10^{6} \mathrm{~s}^{-1}\right)$.

\subsection{Thermal decomposition of $\mathrm{Li}^{\circ} \mathrm{C}_{60}$ in oven}

Figure 7a shows the measured $\mathrm{Li} @ \mathrm{C}_{60}^{+} / \mathrm{C}_{60}^{+}$intensity ratios as a function of temperature for the measurement series plotted in Figure 5 as "Li@ $\mathrm{C}_{60}$ 1st" and " $\mathrm{Li} @ \mathrm{C}_{60}$ 2nd". The typical measurement time at each temperature was ca. $10 \mathrm{~min}$, however there are temperatures at which the material was held longer (e.g. at ca. $635 \mathrm{~K}$ while other checks were being carried out). The arrows show the order of the measurements. It is clearly seen that the endohedral component of the fullerenes that are emitted from the oven decreases with the temperature (and measurement time). The low ratio measured for the highest temperature in the series continues to decay as the oven is cooled back down again. The ratios obtained for the two series of measurements up until a temperature of ca. $600 \mathrm{~K}$ are similar, indicating that no significant change occurred to the amount of endohedral component in the oven during the first measurement series, although some degradation was caused prior to the measurement due to the long de-gassing time (ca. $20 \mathrm{~h}$ ) at $590 \mathrm{~K}$ giving a starting value of the $\mathrm{Li} @ \mathrm{C}_{60}^{+} / \mathrm{C}_{60}^{+}$ratio of ca. 2.3. The second series extended to higher temperatures and shows a strong decrease in the ratio from 2.3 at the start (corresponding to $\left.70 \% \mathrm{Li}_{0} \mathrm{C}_{60}\right)$ to 0.3 at the end of the measurements $\left(23 \% \mathrm{Li} @ \mathrm{C}_{60}\right)$. Figure $7 \mathrm{~b}$ shows the same data from "Li@ $\mathrm{C}_{60}$ 2nd" along with calculations (dashed and full lines) of the expected ratio. The full line provides the best fit to the data with values of $A=3.8 \times 10^{6} \mathrm{~s}^{-1}$ and $E_{\mathrm{a}}=1.285 \mathrm{eV}$, while constraining the fit to remain within the appropriate range to describe the STM experiments, $k(570 \mathrm{~K})=1.74 \times 10^{-5} \mathrm{~s}^{-1}$. The dashed lines indicate the range for these values to still be compatible with the trend observed in the experimental measurements, with $A=(3.8 \pm 0.2) \times 10^{6} \mathrm{~s}^{-1}, E_{\mathrm{a}}=1.285 \pm 0.005 \mathrm{eV}$ and $k(570 \mathrm{~K})=(1.74 \pm 0.26) \times 10^{-5} \mathrm{~s}^{-1}$, indicating the sensitivity of the fit to the three parameters. Note also that the optimum fit values are dependent on the model assumed to extract $k$. A similar analysis using the 3D diffusion model to fit the STM data (giving a smaller value for $k$ ) provided a poorer fit to the decay data shown in Figure 7, predicting a more rapid drop in the detected ratio at higher temperatures. The only other fit parameter is the combination of the photoionisation and detection probability of $\mathrm{Li}_{0} \mathrm{C}_{60}$ compared to $\mathrm{C}_{60}$ that changes the absolute value of the ratio measured in the gas phase experiments but does not influence the dependence on temperature/time. The fit in Figure $7 \mathrm{~b}$ uses a detection ratio of $\mathrm{Li} @ \mathrm{C}_{60} / \mathrm{C}_{60}=6$ at the wavelength of $267 \mathrm{~nm}$. The calculations take account of all prior heating stages, including the $20 \mathrm{~h}$ of de-gassing at $590 \mathrm{~K}$ and the heating that took place during the first series of measurements. Very good agreement is obtained with the experimental data up to a temperature of $700 \mathrm{~K}$. The simple model, however, over-estimates the decay that continues to happen at higher temperatures. It is striking that such a simple model can provide such good agreement with all the experimental observations and allow predictions of the decay of the endohedral species within a temperature range that is relevant for preparation of gas phase targets or deposition of thin films.

\section{Conclusion}

We have shown that it is possible to sublime neutral $\mathrm{Li}_{0} \mathrm{C}_{60}$ and $\mathrm{C}_{60}$ from commercially available $\left[\mathrm{Li}^{+} @ \mathrm{C}_{60}\right] \mathrm{PF}_{6}^{-}$. In order to obtain a "clean" molecular beam it is necessary to heat the material at a low temperature for many hours to remove components related to the stabilising anion and solvent residues ("de-gassing"). This treatment leads to thermal decay of the material in the oven, reducing the $\mathrm{Li}_{0} \mathrm{C}_{60}$ component and leading to the formation of an insoluble component. We have characterised this decay by carrying out mass spectrometry studies using gentle 2-photon ionisation with $267 \mathrm{~nm}$, $100 \mathrm{fs}$ laser pulses, to monitor the relative intensity of $\mathrm{Li} @ \mathrm{C}_{60}$ and $\mathrm{C}_{60}$ in the beam of material and used the 
presence of photoionised "free" Li to determine the activation energy for the decay process. Complementary STM experiments allowed us to directly determine the numbers of $\mathrm{Li}_{0} \mathrm{C}_{60}$ and $\mathrm{C}_{60}$ molecules deposited on a substrate for the de-gassing temperature used in the STM experiments $(570 \mathrm{~K})$. The percentage of $\mathrm{Li}_{0} \mathrm{C}_{60}$ observed was then used to extract an effective rate constant for the decomposition reaction at $570 \mathrm{~K}$. By combining the gas phase and STM experiments it was possible to fit the decrease in the observed $\mathrm{Li} @ \mathrm{C}_{60} / \mathrm{C}_{60}$ ratio in the mass spectra as a function of temperature and time of heating. More detailed studies are required to obtain further insight into the mechanism of the reaction(s) happening within the oven but the data provided in this paper provides a useful practical means of estimating the remaining $\mathrm{Li} @ \mathrm{C}_{60}$ that is available in the gas phase or deposited on a substrate as a function of the thermal treatment that the $\left[\mathrm{Li}^{+} @ \mathrm{C}_{60}\right] \mathrm{PF}_{6}^{-}$material has been exposed to.

The authors gratefully acknowledge Idea International Inc., Sendai, for providing a sample of $\left[\mathrm{Li}^{+} @ \mathrm{C}_{60}\right] \mathrm{PF}_{6}^{-}$. R.S. acknowledges financial support from the Scottish Funding Council thorugh SRD-grant (HR07003) and H.J.C. from an EPSRC DTG studentship (EP/M508214/1). E.C. thanks E. Williams for help with the gas phase measurements and A.V. Gromov for providing the Raman spectra provided in the Supplementary Material.

\section{Author contribution statement}

E.C. performed and analysed the gas phase mass spectrometry experiments and the data modelling. R.S. and H.J.C. performed and analysed the STM experiments. All authors contributed to writing the paper.

\section{Availability of data and materials}

Electronic supplementary information (SI) available: Raman spectroscopy and MALDI mass spectrometry. Experimental data files pertaining to Figures $2-7$ are available at https://doi.org/10.7488/ds/2804.

Publisher's Note The EPJ Publishers remain neutral with regard to jurisdictional claims in published maps and institutional affiliations.

Open Access This is an open access article distributed under the terms of the Creative Commons Attribution License (https://creativecommons.org/licenses/by/4.0/), which permits unrestricted use, distribution, and reproduction in any medium, provided the original work is properly cited.

\section{References}

1. H. Shinohara, N. Tagmatarchis, Endohedral Metallofullerenes: Fullerenes with Metal Inside (John Wiley \& Sons Ltd., 2015)

2. A.A. Popov, Endohedral Fullerenes: Electron Transfer and Spin (Springer, 2017)

3. R. Tellgmann, N. Krawez, S.H. Lin, I.V. Hertel, E.E.B. Campbell, Nature 382, 407 (1996)

4. A. Gromov, D. Ostrovskii, A. Lassesson, M. Jönsson, E.E.B. Campbell, J. Phys. Chem. B 107, 11290 (2003)

5. S. Aoyagi, E. Nishibori, H. Sawa, K. Sugimoto, M. Takata, Y. Miyata, R. Kitaura, H. Shinohara, H. Okada, T. Sakai, Y. Ono, K. Kawachi, K. Yokoo, S. Ono, K. Omote, Y. Kasama, S. Ishikawa, T. Komuro, H. Tobita, Nat. Chem. 2, $678(2010)$

6. H. Okada, T. Komuro, T. Sakai, Y. Matsuo, Y. Ono, K. Omote, K. Yokoo, K. Kawachi, Y. Kasama, S. Ono, R. Hatakeyama, T. Kaneko, H. Tobita, RSC Adv. 2, 10624 (2012)

7. Y. Matsuo, H. Okada, H. Ueno, Endohedral LithiumContaining Fullerenes (Springer, 2017)

8. M. Stefanou, H.J. Chandler, B. Mignolet, E. Williams, S.A. Nanoh, J.O.F. Thompson, F. Remacle, R. Schaub, E.E.B. Campbell, Nanoscale 11, 2668 (2019)

9. H.J. Chandler, M. Stefanou, E.E.B. Campbell, R. Schaub, Nat. Commun. 10, 2283 (2019)

10. J. de Vries, H. Steger, B. Kamke, C. Menzel, B. Weisser, W. Kamke, I.V. Hertel, Chem. Phys. Lett. 188, 159 (1992)

11. H. Yagi, N. Ogasawara, M. Zenki, T. Miyazaki, S. Hino, Chem. Phys. Lett. 651, 124 (2016)

12. V. Piacente, G. Gigli, P. Scardala, A. Giustini, D. Ferro, J. Phys. Chem. 99, 14052 (1995)

13. A. Popović, G. Dražič, J. Marsel, Rapid Commun. Mass Spectrom. 8, 985 (1994)

14. H. Pauly, Atom, Molecule and Cluster Beams I (Springer Verlag, Berlin Heidelberg, 2000)

15. N. Krawez, A. Gromov, K. Buttke, E.E.B. Campbell, Eur. Phys. J. D 9, 345 (1999)

16. E.E.B. Campbell, in Endofullerenes: A New Family of Carbon Clusters, edited by T. Akasaka, S. Nagase (Springer, Dordrecht, 2002), Vol. 3, pp. 67-97

17. C.K. Mathews, M.S. Baba, T.S.L. Narasimhan, R. Balasubramanian, N. Sivaraman, T.G. Srinivasan, P.R.V. Rao, J. Phys. Chem. 96, 3566 (1992)

18. A. Stibor, H. Schefzyk, J. Fortágh, Phys. Chem. Chem. Phys. 12, 13076 (2010)

19. A. Deyko, K.R.J. Lovelock, J.-A. Corfield, A.W. Taylor, P.N. Gooden, I.J. Villar-Garcia, P. Licence, R.G. Jones, V.G. Krasovskiy, E.A. Chernikova, L.M. Kustov, Phys. Chem. Chem. Phys. 11, 8544 (2009)

20. M.I. Bagatskii, V.V. Sumarokov, M.S. Barabashko, A.V. Dolbin, B. Sundqvist, Low Temp. Phys. 41, 630 (2015)

21. A. Khawam, D.R. Flanagan, J. Phys. Chem. B 110, 17315 (2006) 